\title{
A comment on postmortem interrogation of cardiac implantable electronic devices
}

\author{
Milos Kesek $^{1,2}$ (D) \\ Received: 9 July 2019 / Accepted: 26 July 2019/Published online: 6 August 2019 \\ (C) Springer-Verlag GmbH Germany, part of Springer Nature 2019
}

Sirs,

I have a few comments to the very interesting paper by Riesinger L. et al. in the recent issue of Int J Legal Med [1]. The authors describe the time course of thoracic impedance that is stored in some devices (Fig. 3). A simpler generic parameter is the impedance in the pacing and shock circuits (pacing lead impedance and shock impedance). Daily automatic measurements of the lead impedance are stored in virtually all CIEDs and have been shown to increase significantly within the first day postmortem [2].

The devices are complex and the various brands and models differ in their strategies for measurement and storage. OptiVol, mentioned by the authors, is a brand-specific measure (Medtronic Inc., Minneapolis, MN, USA). It cannot be stressed enough (as the authors indeed do) that the forensic CIED analysis should be performed by an experienced arrhythmologist. Adequate interpretation requires a good knowledge of the device. Some knowledge of the previous clinical condition (indication for implantation, pacing need) is of great help. Necessary technical support can be obtained from the manufacturer who can provide specific data about a device model. Sometimes, the manufacturer can on request

Milos Kesek

milos.kesek@medicin.umu.se

1 Department of Medical Sciences and Heart Centre, Umeå University, Umeå, Sweden

2 Arrhythmia Unit, Heart Centre, University Hospital, S-901 85 Umeå, Sweden extract more detailed information from a file dump from the device.

The mode of time detection of the device merits caution. The clock setting should be controlled at the interrogation, as interpretation of time data in devices with internal absolute clock relies on the clock setting.

In my opinion, the interrogation in cases of importance should preferably be done in situ even if practically complicated. Explantation generates artefacts that often will be interpreted by the device as an arrhythmia episode. In the worst case, these artefacts will fill the memory and push out significant previous arrhythmia episodes. Riesinger L. et al. [1] have performed a retrospective interrogation of explanted devices, with the interpreter being blinded to the clinical data, the estimated time of death, and the autopsy results. More precise information can be retrieved in a clinical setting with knowledge of these data and interrogation in situ. A prospective study would be valuable for confirmation of the approach.

\section{References}

1. Riesinger L, Fichtner S, Schuhmann CG et al (2019) Postmortem interrogation of cardiac implantable electrical devices may clarify time and cause of death. Int J Legal Med 133:883-888. https://doi. org/10.1007/s00414-018-1932-3

2. Stroobandt RX, Van Heuverswyn FE, Kucher A, Barold SS (2012) Rise in ICD shock impedance: lead fracture or death? Pacing Clin Electrophysiol 35:1103-1110. https://doi.org/10.1111/j.1540-8159. 2012.03450.x

Publisher's note Springer Nature remains neutral with regard to jurisdictional claims in published maps and institutional affiliations. 